\title{
Dyeing of cotton fabric with ground water and sea water: comparison of their fastness properties
}

\begin{abstract}
A little variation in dyeing procedure applied when fabric dyed with ground water and sea water. When ground water from natural sources used as dyeing medium wetting agents, sequestering agents, anti- creasing agents, salt, soda everything were applied to complete dyeing process. But in case of sea water we didn't apply sequestering agents so that the hardness of sea water might not be broken. Again Bay of Bengal water contains a lot of salts, so it wasn't needed to use salts for dyeing with sea water. The main purpose of our research was to find out the differences in several physical and chemical properties of dyed fabrics and to determine whether can be used sea water as dyeing medium for dyeing process. Sea water is available in Bangladesh. Again due to lack of ground water availability the layer of our ground water falls down every year. So, it has become a crying need to find out another alternative source of water to continue our industrial dyeing process. For this purpose we wanted to find out the possibilities and opportunities of using sea water as dyeing medium instead of ground water.
\end{abstract}

Keywords: cotton, ground water, sea water, reactive dye, shade variation, reflectance \%, color fastness, color strength
Volume 5 Issue 6 - 2019

\author{
Md Solaiman,' Sakib Mahmud Surid, ${ }^{2}$ Md \\ Abu Sayed Patwary, ${ }^{2}$ Md Habibur Rahman, ${ }^{2}$ \\ Puja Sinha, ${ }^{2}$ Md Belal Hossain, ${ }^{2}$ Md Maksudur \\ Rahman ${ }^{2}$ \\ 'Department of Fabric Manufacturing Engineering, Textile \\ Engineering College, Noakhali affiliated by Bangladesh University \\ of Textiles, Bangladesh \\ ${ }^{2}$ Department of Wet Processing Engineering, Textile Engineering \\ College, Noakhali affiliated by Bangladesh University of Textiles, \\ Bangladesh
}

\begin{abstract}
Correspondence: Sakib Mahmud Surid, Department of Wet Processing Engineering, Textile Engineering College, Noakhali affiliated by Bangladesh University of Textiles, Dhaka- 1208, Bangladesh, Tel +880 I52 I44I777,

Email Sakibmahmud950@gmail.com
\end{abstract}

Received: October 31, 2019 | Published: November 18, 2019

\section{Introduction}

Water, a substance composed of the chemical elements hydrogen and oxygen and existing in gaseous, liquid, and solid states. It is one of the most plentiful and essential of compounds. Processes such as mining, chemical pulping, pulp bleaching, paper manufacturing, textile production, dyeing, printing, and cooling of power plants use large amounts of water, requiring a dedicated water source, and often cause significant water pollution. Water is used extensively throughout textile processing operations. The Textile industry is dependent on water in virtually all steps of manufacturing. Textile industry is the third largest consumer of water in the world. Wet processing engineering is one of the major streams in textile engineering. In every stages of wet processing huge amount of water is used. Most fabric preparation steps, including desizing, scouring, bleaching and mercerizing use water. According to the latest FAO data on sectoral water use, Bangladesh total annual freshwater withdrawal in 2014 was 35.87 billion cubic meter in which total industrial water use only accounted for about $2.147 \%$ of Bangladesh total water use, while agricultural sector is the largest water use with $87.82 \%$ followed by domestic water use of $10.04 \%$. It is projected that industrial water demand can increase by $109 \%$, domestic water demand by $75 \%$ and agricultural water demand by $43 \%$ in $2030 .{ }^{1}$ Textile and RMG industry is the main contributor to that industrial water demand. Most industrial water is sourced from groundwater (estimated at $98 \%{ }^{2}$ ). About $90 \%$ of urban water supply is also sourced from groundwater. ${ }^{3}$ From a report on Daily star newspaper, it is seen that, the groundwater level in the capital has dropped by six meters in the last seven years. ${ }^{4}$ The main purposes of using sea water as dyeing medium are to reduce the use of ground water and reduction in requirement of sequestering agents and salts. In this work, it can also be seen that reducing the dependency on ground water and instead of ground water how successfully a dyeing process of cotton fabric with reactive dye can be done by using sea water. Dyeing of cotton fabric with sea water is one of the possible options to reduce the dependency on the ground water. Sea water was collected from cox's bazar sea beach used as raw with $\mathrm{pH}$ of 7-8, hardness was about 3.94g/L and TDS was 20920 PPM $(2100 \mathrm{~g} / \mathrm{L})$. The six most abundant ions of seawater are chloride $(\mathrm{Cl}-)$, sodium $(\mathrm{Na}+)$, sulfate $\left(\mathrm{SO}_{4}^{2}-\right)$, magnesium $\left(\mathrm{Mg}^{2+}\right)$, calcium $\left(\mathrm{Ca}^{2}+\right)$, and potassium $(\mathrm{K}+)$. By weight these ions make up about $99 \%$ of all sea salts. Seawater contains more dissolved ions than all types of freshwater. ${ }^{5}$

However, the ratios of solutes differ dramatically. For instance, although seawater contains about 2.8 times more bicarbonate than river water, the percentage of bicarbonate in seawater as a ratio of all dissolved ions is far lower than in river water. Bicarbonate ions constitute $48 \%$ of river water solutes but only $0.14 \%$ for seawater. ${ }^{5,6}$ Differences like these are due to the varying residence times of seawater solutes; sodium and chloride have very long residence times, while calcium (vital for carbonate formation) tends to precipitate much more quickly. ${ }^{7}$ The most abundant dissolved ions in seawater are sodium, chloride, magnesium, sulfate and calcium. ${ }^{8}$ In this study, we have analyzed the influenced of sea water and ground water during the dyeing process of the samples. The main target of the work was how we can reduce using of ground water during dyeing.

\section{Materials and methods}

\section{Materials}

For this experiment, we used $100 \%$ single jersey cotton fabric of $140 \mathrm{GSM}$, count of yarn was 30/1, and stitch length was $2.6 \mathrm{~mm}$. Fabrics for the dyeing of samples were collected from Interstoff Apparels Limited, Chandra, Gazipur, Dhaka, Bangladesh. Two types of water 
were used for the experiment, one using sea water was collected from the Bay of Bengal off the South East coast of Bangladesh with $\mathrm{pH}$ of $7-8$, hardness is about $3.94 \mathrm{~g} / \mathrm{L}$ and TDS is 20920 PPM $(2100 \mathrm{~g} / \mathrm{L})$. The final target of this work was to compare the effects of fastness properties between dyed fabric with normal water and dyed fabric with sea water. Color fastness tester, Beesley's balance, Crocking meter, Stop watch, ICI pilling tester and Spectrophotometer were used to do the physical, mechanical and visual properties of the $100 \%$ cotton single jersey fabric. In the pretreatment stage of dyeing, Wetting agent (Deterpal HW), sequestering agent (Sequestrante 549), Anti-creasing agent (Novolube PAN 200), Stabilizer (Perox PAG), Sodium Hydroxide (Natrium Hydroxide), $\mathrm{H}_{2} \mathrm{O}_{2}$ (Product BSS), Soda ash (Natrium-bi-carbonate), Peroxide killer (Oxitase Kp) and Acetic acid were used. For the dyeing stage and the after treatment stage respectively Ground water, Sea water from Bay of Bengal, Wetting agent (Deterpal HW), sequestering agent (Sequestrante 549), Anticreasing agent (Novolube PAN 200), Scarlet Dye (Scarlet 3GF), Levelling agent(Permacol RK), Glauber salt, Soda ash and Acetic acid, Detergent (Deterpal HW), Fixing agent (Novofix CT/HYP) were also used.

\section{Methods of the experiments}

Scouring and bleaching process of cotton fabric: Set the bath with substrate at room temperature with wetting agent, sequestering agent and anti-creasing agent. Then load 40gm 100\% cotton single jersey fabric in the pot. After 5 minutes added soda ash and $\mathrm{NaOH}$. Again after 5 minutes added $\mathrm{H}_{2} \mathrm{O}_{2}$ and raised the temperature to $100^{\circ} \mathrm{C}$. After reaching $100^{\circ} \mathrm{C}$ temperature, run for 40 minutes at the same temperature. After that lowered the temperature at $50^{\circ} \mathrm{C}$ and rinsed for
10 minutes then dropped the liquor. Again raised the temperature at $80^{\circ} \mathrm{C}$ gradually, applied $\mathrm{H}_{2} \mathrm{O}_{2}$ killer and run for 10 minutes. After then lowered the temperature at $50^{\circ} \mathrm{C}$ and rinsed for 10 minutes. Finally treated the sample with acetic acid for 10 minutes at $60^{\circ} \mathrm{C}$ temperature to make the sample neutral and then rinsed with cold water again (Figure 1).

Dyeing with ground water: At first in room temperature, ground water, wetting agent, sequestering agent and anti-creasing agents were mixed in dyeing bath. Then fabric sample was immerged here. Dyes mixed in the dyeing bath. Temperature was increased gradually up to $80^{\circ} \mathrm{C}$. Salt was added when temperature increasing. At $80^{\circ} \mathrm{C}$ temperature, soda ash dosed and run about 60 minutes. Then cool down the bath and rinsed fabric at $50^{\circ} \mathrm{C}$. Fabric was treated with Acetic acid to neutralize it. Then temperature increased and at $90^{\circ} \mathrm{C}$, detergent was added. Then rinsed the fabric at $50^{\circ} \mathrm{C}$ temperature. After all fixing agent was mixed in dye bath at $60^{\circ} \mathrm{C}$ temperature for 10 minutes to fix the dye molecules with fabric (Figure 2).

\section{Dyeing with sea water}

At first in room temperature, sea water, wetting agent and anticreasing agents were mixed in dyeing bath. Then fabric sample was immerged here. Dyes mixed in the dyeing bath. Temperature was increased gradually up to $80^{\circ} \mathrm{C}$. At $80^{\circ} \mathrm{C}$ temperature, soda ash dosed and run about 60 minutes. Then cool down the bath and rinsed fabric at $50^{\circ} \mathrm{C}$. Fabric was treated with Acetic acid to neutralize it. Then temperature increased and at $90^{\circ} \mathrm{C}$, detergent was added. Then rinsed the fabric at $50^{\circ} \mathrm{C}$ temperature. After all fixing agent was mixed in dye bath at $60^{\circ} \mathrm{C}$ temperature for 10 minutes to fix the dye molecules with fabric (Figure 3).

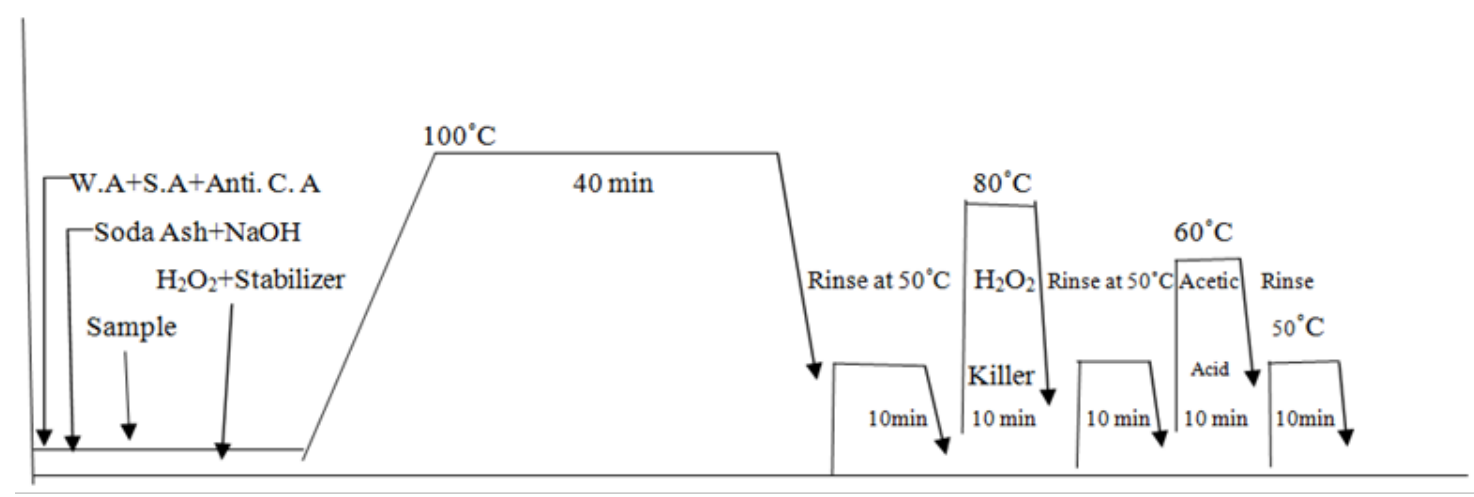

Figure I Scouring and bleaching curve.

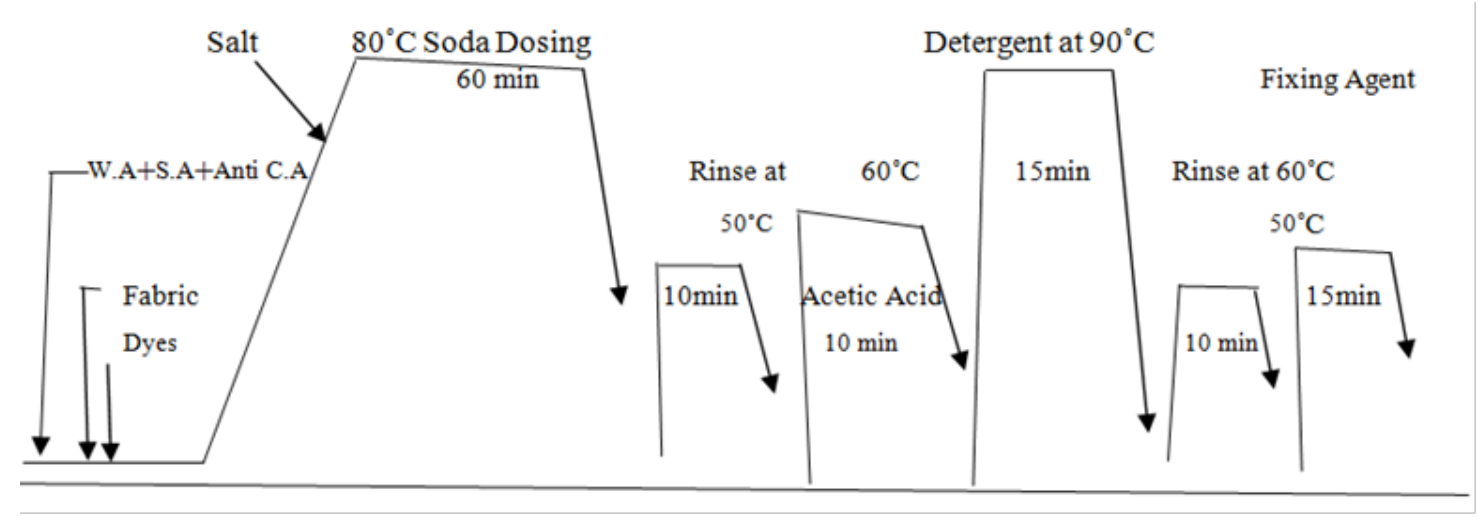

Figure 2 Dyeing process Curve (with Ground water). 


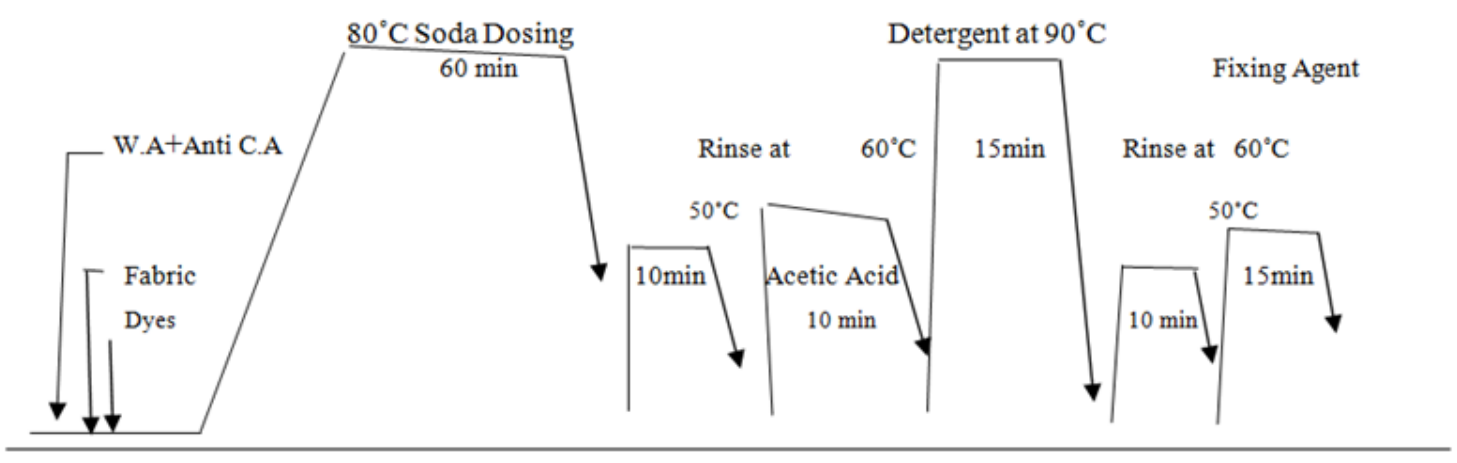

Figure 3 Dyeing process Curve (with Sea water).

\section{Test procedures}

Testing procedure of reflectance \% of dyed samples: The reflectance percentages of ground water dyed samples and sea water dyed samples were measured and compared using a UV VIS-NIR reflective spectrometer (Spectra Flash SF $600 \mathrm{X}$, USA), over the range of $400 \mathrm{~nm}$ to $700 \mathrm{~nm}$.

Testing procedure of color strength: The color intensities of ground water dyed fabric and sea water dyed fabric for a specific design and construction, fabrics were measured and compared using a UV VISNIR reflective spectrometer (Spectra Flash SF 600 X, USA), over the range of $400 \mathrm{~nm}$ to $700 \mathrm{~nm}$.

\section{Testing procedure of colorfastness to rubbing (ISO I05XI2; 1993; BS EN ISO I05XI 2; | 995)}

Test specimen: Two pieces of $14 \mathrm{~cm} \times 5 \mathrm{~cm}$ specimens are required for dry rubbing and two for wet rubbing test.

\section{Test procedure}

Dry rubbing test: Lock the test specimen onto the base of the Crockmeter so that it lies flat and taut for test and taut for testing. Using the spiral clip, set a $5 \mathrm{~cm} \times 5 \mathrm{~cm}$ square of the white rubbing test cloth to set the finger of the Crockmeter. Lower the covered finger onto the test sample. Turn the hand crank and make ten complete turns of the crank, at the rate of one turn per second. Remove the white rubbing test specimen cloth from the finger and evaluate color transfer using the gray scale for staining under standard lighting, D65.

Wet rubbing test: Repeated the procedure on another sample with the white test cloth wetted in distilled water. Ensured that the rubbing test cloth would be wetted with water to $100 \%$ take up. Air dried the $100 \%$ cotton single jersey test cloth at the room temperature before evaluation.

\section{Testing procedure of color fastness to washing (ISO I05 C06)}

Test specimen: Sample Fabric: $10 \mathrm{~cm} \times 4 \mathrm{~cm}$

Multi fiber fabric: $10 \mathrm{~cm} \times 4 \mathrm{~cm}$

\section{Test procedure}

Collect the sample from bulk and then conditioning for 04:30 hours to 06 hours. Make a specimen of $10 \mathrm{~cm} \times 4 \mathrm{~cm}$ in size. Sew the specimen with multi-fiber fabric of same size at one corner. Make the solution of $4 \mathrm{gm} /$ litre ECE detergent \& $1 \mathrm{gm} /$ litre sodium perborate.
Put the specimen with multi-fibre fabric into the solution in Rotary washing $\mathrm{m} / \mathrm{c}$ and taking temp: $60^{\circ} \mathrm{C}$ at $30 \mathrm{~min}$ with $25 \mathrm{pcs}$ still ball. Rinse with hot water respectively. Squeeze with cold water of the sample is done (Hand Wash). Then drying is done at a temperature in the air not exceeding $60^{\circ} \mathrm{C}$. The stitching is then broken out except on one of the shorter end. Measure the staining and color change by grey scale \& make a test report.

\section{Testing procedure of pilling test (ICI Pilling Box) (ISO (2945-I)}

Test Specimen: Sample Fabric: 5" $\times 5$ "

\section{Test procedure}

The sample is sewn so as to be firm fit when placed a rubber tube 6 " long, 1.25 " outer diameter and 0.125 " thick. The cut ends of the fabric are covered by cellophane tape and 4 tubes are placed in a box $(9$ " $\times 9$ " $\times 9$ ") lined with cork 0.125 " thick. The box containing the tube is then rotated at $60 \mathrm{rpm}$ for 5 hours. After tumbling, the extent of pilling assessed visually comparison with the arbitrary standards.

\section{Testing procedure of water takes up percentage (ASTM D-570)}

Test specimen: Make a sample at a dimension of $2 \mathrm{~cm}$ in length $\times 1 \mathrm{~cm}$ in width.

\section{Test procedure}

Composite samples were immersed in a beaker containing $100 \mathrm{ml}$ of deionized water at room temperature for 1 hour. Initially, weight of samples was determined, after certain time interval; samples were taken out of the beaker and wiped using tissue papers. Their weight was taken again. In this case, it shows no uptake after 40 minutes; that why carried out the test up to 1 hour water uptake percentage was determined by using following equation- Water take up percentage $=$ [Wet weight-Dry weight)/Dry weight] $\times 100$.

\section{Results and discussion}

\section{Comparison on shade\%}

Table 1 showed the dyeing recipe and the shade of each samples dyed with ground water and sea water. The evaluation had been done under D65 light source in the light box. Reactive dyes of cold brand, salt and soda used amount had been mentioned on the table. The amount of salt and soda were calculated according to shade \% those are practically used for the laboratory dyed samples. 
Table I Dyeing recipe and comparative shade between the samples

\begin{tabular}{|c|c|c|}
\hline Recipe & Ground water dyed samples & Sea water dyed samples \\
\hline \multicolumn{3}{|l|}{ Scarlet 3GF- 3\% } \\
\hline \multicolumn{3}{|l|}{ Wetting agent- Ig/L } \\
\hline \multicolumn{3}{|l|}{ Sequestering agent- $0.5 \mathrm{~g} / \mathrm{L}$ (sample I) } \\
\hline \multicolumn{3}{|l|}{ Anti-creasing agent- Ig/L } \\
\hline \multicolumn{3}{|l|}{ Salt- 80g/L(sample I) } \\
\hline \multicolumn{3}{|l|}{ Soda ash- 20g/L } \\
\hline \multicolumn{3}{|l|}{ Scarlet 3GF- $2 \%$} \\
\hline \multicolumn{3}{|l|}{ Wetting Agent- Ig/L } \\
\hline \multicolumn{3}{|l|}{ Sequestering agent- $0.5 \mathrm{~g} / \mathrm{L}$ (sample I) } \\
\hline \multicolumn{3}{|l|}{ Anti-creasing agent- Ig/L } \\
\hline \multicolumn{3}{|l|}{ Salt- 50g/L(sample I) } \\
\hline Soda ash- $12 \mathrm{~g} / \mathrm{L}$ & Sample 2 & Sample 4 \\
\hline
\end{tabular}

\section{Reflectance percentage of dyed samples}

Obtained reflectance percentages are plotted on graph for sample 1, 2, 3, 4 (Figure 4) (Figure 5). Sample 1 and 3 showed reflectance for dark shade and sample 2 and 4 showed reflectance for medium shade of fabrics dyed with ground water and sea water respectively. Considering dark shades sample 1 showed reflectance value $82.469 \%$ where the value increased about $1.77 \%$ in case of sea water (sample 3).Again for medium shades sample 2 showed reflectance value $81.494 \%$ where the value increased about $4.09 \%$ in case of sea water (sample 4).Reflectance values increases for sea water dyed samples comparing with ground water dyed samples.

\section{Reflectance $\%$ of $3 \%$ shade dyed samples}

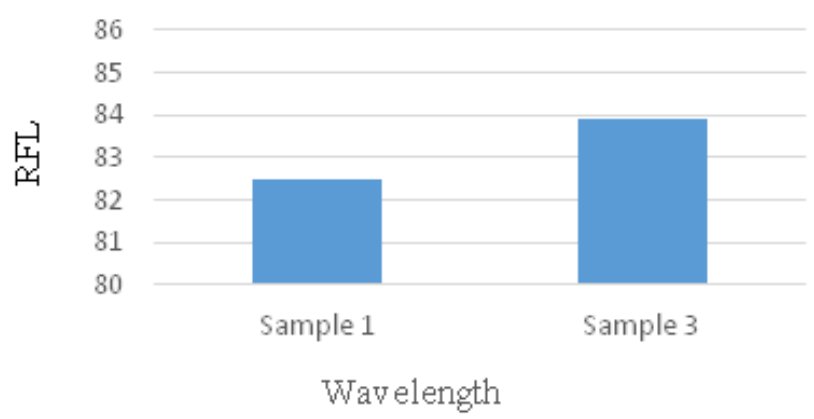

Figure 4 Graphical representation of reflectance\% of $3 \%$ shade dyed samples with respectively ground water and sea water.
Reflectance $\%$ of $2 \%$ shade dyed samples

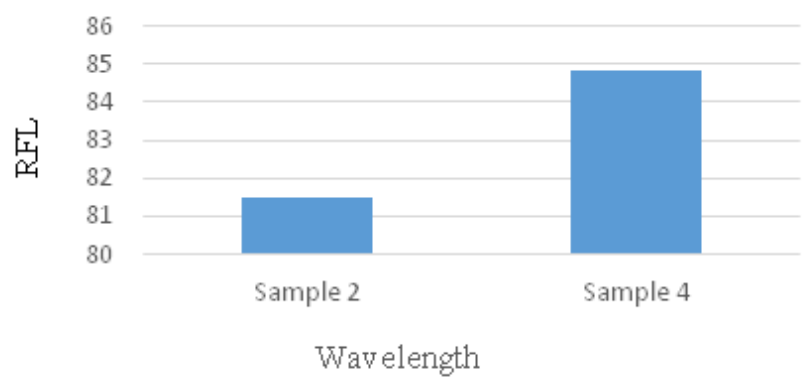

Figure 5 Graphical representation of reflectance\% of $2 \%$ shade dyed samples with respectively ground water and sea water.

\section{K/S values of dyed samples}

Obtained K/S values are plotted on graph for samples 1, 2, 3 and 4 (Figure 6) (Figure 7). For dark shades, we found K/S value 0.019 when using ground water (sample 1) and the value found 0.015 when using sea water (sample 3). Again considering medium shades, we found $\mathrm{K} / \mathrm{S}$ value 0.021 in case of ground water(sample 2) and the value showed 0.014 for sea water as dyeing medium(sample 4). K/S values decreases for sea water dyed samples comparing with ground water dyed samples.

\section{Determination of colorfastness to rubbing}

This test was designed to determine the degree of color which may be transferred from the surface of a colored fabric to specify test cloth for rubbing (which could be dry and wet). 


\section{$\mathrm{K} / \mathrm{S}$ values of $3 \%$ shade dyed samples}

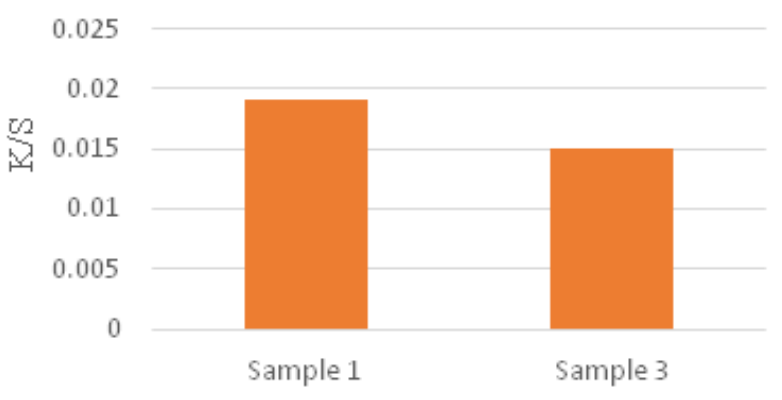

Wav elength
$\mathrm{K} / \mathrm{S}$ values of $2 \%$ shade dyed samples

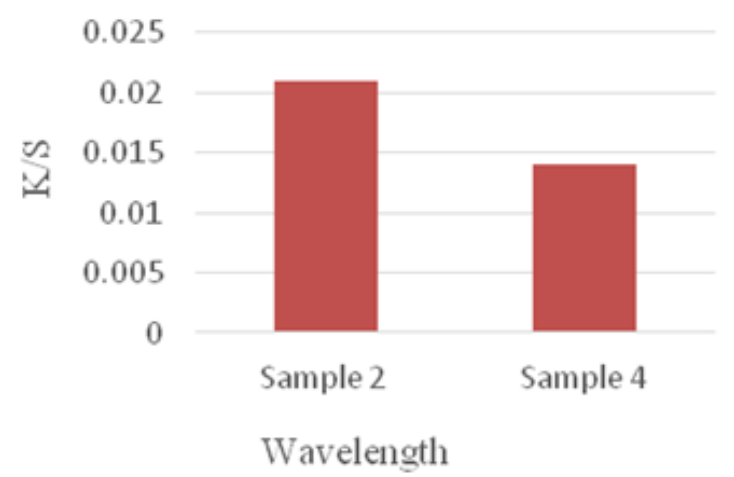

Figure 7 Graphical representation of $\mathrm{k} / \mathrm{s}$ of $2 \%$ shade dyed samples respectively with ground and sea water.

using sea water showed also excellent fastness at the dry condition. But at the wet condition, first sample wherein ground water was used as liquor showed not excellent but good fastness quality. Same as at the wet condition, second sample wherein sea water was used as liquor showed good fastness quality (Table 2).

Table 2 Results of colorfastness to rubbing of the samples

\begin{tabular}{lllll}
\hline & \multicolumn{2}{l}{ Dry condition rubbing result } & Wet condition rubbing result \\
\cline { 2 - 5 } SI. No & $\begin{array}{l}\text { Ground water dyed } \\
\text { samples. }\end{array}$ & $\begin{array}{l}\text { Sea water dyed } \\
\text { samples. }\end{array}$ & $\begin{array}{l}\text { Ground water dyed } \\
\text { samples. }\end{array}$ & $\begin{array}{l}\text { Sea water dyed } \\
\text { samples. }\end{array}$ \\
\hline I & 5 & 5 & $4 / 5$ & $4 / 5$ \\
2 & 5 & 5 & $4 / 5$ & $4 / 5$ \\
Average & $\mathbf{5}$ & $\mathbf{5}$ & $\mathbf{4 / 5}$ & $\mathbf{4 / 5}$ \\
\hline
\end{tabular}

\section{Determination of color fastness to washing}

From the Table 3 and Table 4, it was found that dyes stained on the fibers of the multifibre fabric showed the rating was almost same for both fabrics. The staining on the di-acetate, bleached cotton, polyester, acrylic for $100 \%$ cotton single jersey fabric dyed with reactive dye with ground water and sea water both showed almost the same result.

Table 3 Results of Color staining of $3 \%$ shade dyed samples respectively with ground and sea water

\begin{tabular}{lll}
\hline Multifibre's layer & Sample I & Sample 3 \\
\hline Di-acetate & $4 / 5$ & $4 / 5$ \\
Bleached cotton & $4 / 5$ & $4 / 5$ \\
Polyamide & 5 & 4 \\
Polyester & $4 / 5$ & $4 / 5$ \\
Acrylic & $4 / 5$ & $4 / 5$ \\
Wool & 4 & 4
\end{tabular}

There was seen no staining on the polyamide for the samples wherein used ground water as liquor. But the staining on the polyamide for the samples wherein sea water used as liquor was slightly and fastness quality was moderate to good. For the both liquors i.e. ground water and sea water, the staining on the wool was same; moderate to good in fastness quality.

Table 4 Results of color staining of $2 \%$ shade dyed samples respectively with ground and sea water

\begin{tabular}{lll}
\hline Multifibre layers & Sample 2 & Sample 4 \\
\hline Di-acetate & 4 & $4 / 5$ \\
Bleached cotton & $4 / 5$ & $4 / 5$ \\
Polyamide & 5 & $4 / 5$ \\
Polyester & 4 & $4 / 5$ \\
Acrylic & $4 / 5$ & 4 \\
Wool & 4 & 4 \\
\hline
\end{tabular}




\section{Determination of pilling resistance}

Considering dark shade samples (Figure 8), it was seen that the rating of pilling was 1 for both the ground water dyed sample and sea

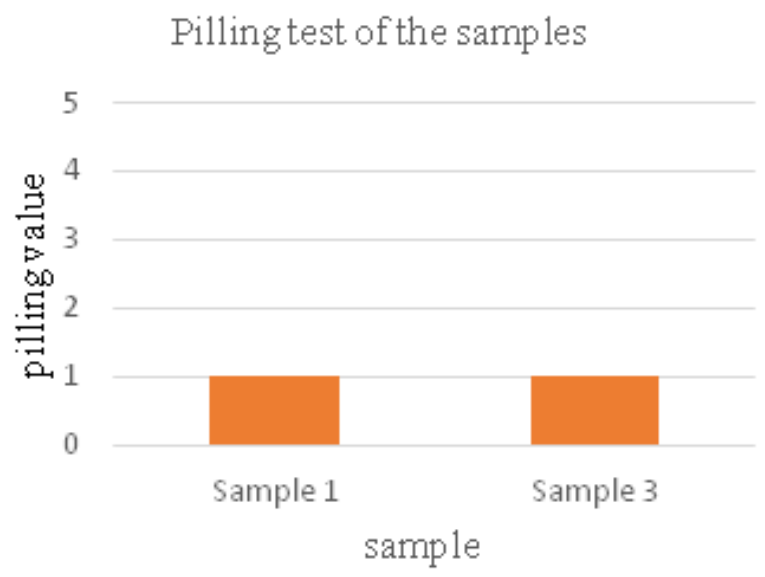

Figure 8 Results of pilling resistance of 3\% shade dyed samples respectively ground and sea water.

\section{Pilling test of the samples}

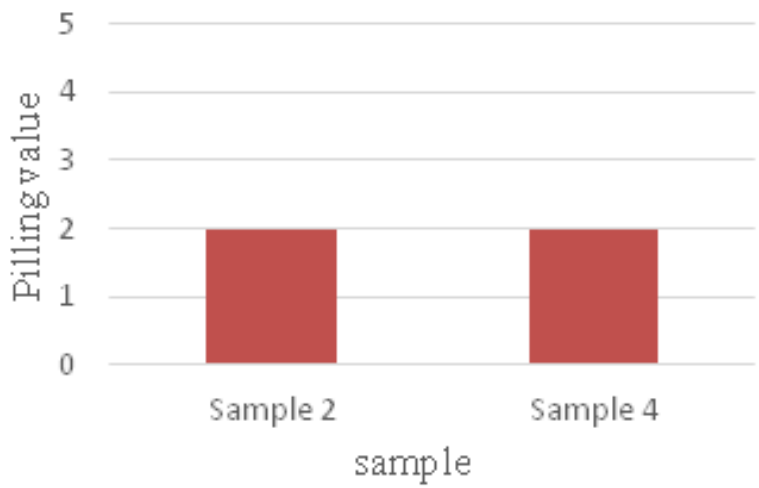

Figure 9 Results of pilling resistance of $2 \%$ shade dyed samples respectively ground and sea water.

\section{Determination of water takes up percentage}

From Table 5 and Table 6 , it was seen that water take up $\%$ of ground water dyed sample was greater than sea water dyed sample because fabric resisted a small volume of sea water cause of some particles of sea water couldn't penetrate into the fabric.

Table 5 Results of water take up\% of 3\% shade dyed samples with respectively ground and sea water

\begin{tabular}{llll}
\hline Samples & Dry weight & Wet weight & Water take up \% \\
\hline Sample I & $2 \mathrm{gm}$ & $4.40 \mathrm{gm}$ & $120 \%$ \\
Sample 3 & $2 \mathrm{gm}$ & $4.19 \mathrm{gm}$ & $109 \%$ \\
\hline
\end{tabular}

water dyed sample, which indicates no pilling was formed. Again for medium shade samples (Figure 9) the rating was 2 for both the ground water dyed sample and sea water dyed sample, which indicates slight but tolerable piling.

Table 6 Results of water take up $\%$ of $2 \%$ shade dyed samples with respectively ground and sea water

\begin{tabular}{llll}
\hline Samples & Dry weight & Wet weight & Water take up \% \\
\hline Sample 2 & 1.5gm & $3.30 \mathrm{gm}$ & $120 \% \%$ \\
Sample 4 & $1.5 \mathrm{gm}$ & $3.05 \mathrm{gm}$ & $103 \%$ \\
\hline
\end{tabular}

\section{Conclusion}

In this research we had analyzed several properties of dyed samples where dyeing mediums were ground water and sea water respectively. We have found a little bit of shade variation when fabric dyed with ground water and sea water. Fabric dyed with ground water showed better shade percentage due to higher penetration of dye molecules into fabric samples than sea water dyed samples. Sea water dyed samples reflected more lights than ground water dyed samples i.e. they showed more reflectance. But K/S values found more in case of ground water dyed samples. Color fastness to rubbing was almost same for the samples dyed with ground water and sea water. No problem seen about color fastness to washing. The fastness showed by sea water dyed samples almost same to the fastness showed by ground water dyed samples. In case of dark shades both samples showed better resistance to pill and for medium shades both samples showed a slight tendency to form pill for both samples. Samples dyed with ground water showed better water take up percentage and more tendencies to swell than samples dyed with sea water.

\section{Acknowledgments}

None.

\section{Funding}

None.

\section{Conflicts of interest}

The authors declare that they have no competing interests.

\section{References}

1. Restiani P. Water governance mapping report: textile industry water use in Bangladesh. 2016

2. Sagris T, Abbott J. An analysis of industrial water use in Bangladesh with a focus on the leather and textile industries. Washington DC, USA; 2015 .

3. Danilenko A, Van den Berg C, Macheve B, et al. The IBNET water supply and sanitation blue book 2014: The international benchmarking network for water and sanitation utilities databook. The World Bank; 2014.

4. Dhaka's groundwater drops $6 \mathrm{~m}$ in 7 years. 2011.

5. Kandasamy R, Vignesh V, Kumar A, et al. Thermal radiation energy due to SWCNTs on MHD nano fluid flow in the presence of seawater/ water: lie group transformation. Ain Shams Engineering Journal. 2018;9(4):953-963. 
6. Pinet PR. Invitation to Oceanography. 5th ed. Jones and Bartlett publishers. 1996.

7. Hogan C, Michael. Calcium. In: Jorgensen A, Cleveland C, editors. Encyclopedia of Earth. Some evidence shows the potential for fairly regular ratios of elements maintained across surface oceans in a phenomenon known as the Redfield Ratio. National Council for Science and the Environment. 2010.
8. Bone Q, Ryan KP. Osmolarity of osmium tetroxide and glutaraldehyde fixatives. The Histochemical Journal. 1972;4(4):331-333. 